\title{
Interactive comment on "Structural geology and geophysics as a key to build a hydrogeologic model of granite rock to support a mine" by $L$. Martinez Landa et al.
}

\section{Martinez Landa et al.}

Lurdes.Martinez@upc.edu

Received and published: 19 April 2016

SE-2016-27-RC1-Reply: Replies (in colors for clarify) have been added as a suplementary pdf file.

The paper is of potential interest for Solid Earth and fits the scope of the journal. I highly recommend that a proper hydrogeologist reviews this paper since this is not my field of expertise. "Structural geology and geophysics as a key ...." The truth is that the model could not 
have been built without a strong support of structural geology and geophysics. It is this support what allowed us to extend the conductive fractures beyond the area that was mapped and characterized by hydraulic tests. And it is also this support what allowed us to identify conductive fractures that had not been mapped. All this was explained in section 2.1 .

Having said this, the reviewer is right in that neither structural geology nor geophysics is at the core of the paper. Therefore we have changed the title, which now reads: "Structural geology and geophysics as a support to build a hydrogeologic model of granite rock"

But we have also modified the text to stress the role of structural geology and geophysics. Specifically, we added a paragraph at the end of the section on "geology and geophysics" For the purpose of subsequent hydrogeological analyses, it is important to highlight that (1) the above discussion is the result of a structural geological interpretation of 3D seismics (specifically, direct seismic inversion was often modified after discussions with structural geologists, who pointed to inversion inconsistencies. Therefore, it can be stated that seismic inversion was "structural geologically biased"); (2) some water conducting faults (specifically 474, and 285), were identified during seismic inversion, but had not been mapped because they are located in an area covered by meadows; and (3) geophysics also helped to identify highly fractured zones (e.g., fractured granitic units, fractured belts around the dykes and South faults), which provided hydraulic connectivity.

Also, in response to comments by the other referee, we have added an explanation on which untested fractures were assigned properties of tested fractures.

Fractures not affected by any test were assigned the transmissivities that had been obtained during calibration for fractures belonging to the same family, according to the geophysical and structural analysis. Specifically, fractures 474, 474', 478 and Fr4 were assigned the values obtained for fracture 285 , and the SR3 dyke was assigned the $T$ 
obtained for the not-mined portion of the 27 dyke.

B. The English needs significant improvement before the paper can be accepted. We have had the text revised by a native English speaking person.

MINOR COMMENTS pg 2, lines 1-3: I think reference to the Canadian URL should also be given here. Done, the reference is: Frape, S.K., Fritz, P., and McNutt, R.H.: Waterrock interaction and chemistry of groundwaters from the Canadian shield, Geochim. et Cosmochim. Acta, 48, 1617-1627,1984.

pg 2, line 4: Clarify here, they may have been subjected to tectonics, but not glacial tectonics. Or are they not disturbed at all? We modify the text which now reads: In contrast, sites in Southern Europe have not been subjected to glacial unloading stresses. As a result, most fractures have been driven by much older tectonics (PerezEstaún, et al., 2002; Escuder Viruete, 2003b) and they have been largely filled by mineral precipitates. In addition, saline water has never infiltrated these systems, so that the deep water is of $\mathrm{Na}-\mathrm{HCO} 3$, rather than $\mathrm{Na}-\mathrm{Cl}$ type.

pg 5, line 15: There is no temperature log in Figure 4! Sorry, we had changed the figure giving up some profiles as temperature, $\mathrm{pH}$ and dissolved oxygen, but not the text, which now reads: electrical conductivity, redox potential, resistivity, gamma ray, spontaneous potential, diameter and flow meter We have also modified the caption of Fig.4, which now reads: Some of the chemical and geophysical logs recorded at borehole SR1, which helped to identify dyke 27 and fracture SR1-3. The chemical logs only display the effect of dyke 27, because all upper water (including SR1-3) is mine water. The effect of both structures can be noticed in the other logs, especially in the gamma log, due to fracture filling. Flow meter values, recorded with an upward flow-rate of pumping indicate little water flow beneath dyke 27 . The same applies to a lesser extent to fracture SR1-3.

pg 10, line 11: Provide some quantification of the fit to show that it is excellent. 
Actual errors (mean quadratic error) are shown in the table below:

However, head errors provide a poor description of the fit quality, because errors display more as a delay in response. Therefore, we prefer to simply add that the fit is "visually" excellent. We made a few additional modifications to the text, which now reads:

Overall, the fit of this blind prediction was visually excellent. Nevertheless, it becomes apparent that the estimated specific yield for the South cross-hole test model was too high, which may reflect that the hydraulic characterization of the zone was performed entirely during the winter and within a wet interannual cycle, so that the entire zone was fully saturated. In the prediction, it can be observed that most of the water came from the lehm, which is a very conductive layer with a relatively high specific yield (3.6Âư103 ), while the altered unit specific yield was set at 4.6Âů10-6 m-1. The mine pumping was carried out in the summer, when piezometric heads are lower and the upper units are unsaturated. To test this conjecture, we calibrated these parameters. The fit, not shown, was improved by reducing the storage coefficient of the lehm (4Âů10-5) and increasing the specific storage of the altered unit (1.3Âů10-4 m-1). This artifact reflects that water is withdrawn from the altered unit, which is the actual storage unit in dry periods.

pg 10, line 21: I do not see how the geophysics has demonstrated the existence of the fracture systems in this paper.

As we have explained on the response to the general comments of this review, a good knowledge of the geology is essential to understand correctly how the hydrogeological system works, the main fracture systems, and the connection between them can be derived from geophysical interpretation coupled with structural geology. On a 3D system the only way to know this, outside the surface and borehole logs description, is using the geophysical tools. This technique, together with the observation of other disciplines (all these works are extremely interdisciplinary), constitute the base of a robust geometry that allow reproducing correctly the behavior of the media. This has 
been corroborated with the change on temporal and spatial scale reproduced on the predictive model.

Still, the reviewer is right in that "demonstrate" may a too strong. Instead, we write "show", which may be more appropriate.

pg 11, lines 1-3: I think this is a rather bold statement if it is based on this paper.

Interactive

comment

The original statement was "Results also confirm the conjecture that Southern European granite plutons display low hydraulic conductivity. This, together with the low aggressivity of their sodium bicarbonate groundwater makes them appropriate for hosting nuclear waste". This statement is not solely based in this paper, but also others, cited in the introduction, which we attribute to the lack of glacial unloading effects. We have softened the statement, which now reads: The results are consistent with the hypothesis that Southern European granite plutons display low hydraulic conductivity. This, together with the low aggressivity of their sodium bicarbonate groundwater, makes them appropriate for hosting nuclear waste.

Figure 4: I do not see how the geophysical logs helped identify the dyke. There should be a large difference in the gamma log between the granite and the diabase quartz dyke. Please explain. Resistivity is normally plotted using a log scale (done). Also, the resistivity seems quite low for in-tact granite. Please elaborate on this. These logs are performed at the SR1 borehole, which is located on the not mined part of the 27 quartz dyke, but very close of the mined portion. The granite body is strongly weathered and with a high fracturation index at the first $200 \mathrm{~m}$ depth. It is for this reason that we have made units differentiation inside the granitic body, depending on the state of the granite the hydraulic behavior are different. This explanation could be explaining the measured values. We change the scale of resistivity to log scale. The figure 4 has been modified as follow:

Figure caption 5: The authors state that "S ranges from 1 to 53Âư10-3." The range seems to be much more than this when I look at the figure. It was an error. $S$ ranges 
Figure 7: $\mathrm{K}$ is now used instead of $\mathrm{T}$, this makes comparisons with previous figures

difficult. Here, we had used $\mathrm{K}$ instead of $\mathrm{T}$ because the Stober equation. We have transformed our values of $\mathrm{T}$ to $\mathrm{K}$ dividing by interval length. In the SR5 hydraulic characterization has been $50.81 \mathrm{~m}$ length (distance between packers).

Interactive

Figure 9: It is not clear to me what this figure implies. Are the circles observation points and lines the modelling? Yes, the circles reproduce the observation circles measurements and the lines the modeling results. We modify the caption of the figure 9 as follows: Figure 9: Results obtained after calibrating the SR4-1 cross-hole test are indicated by a black line, observed data are indicated with circles using a 3D model. All graphs maintain the vertical scale to facilitate comparison of the results. Figure 11: Again, some more explanation needed in the figure caption. Yes, the circles reproduce the observation circles measurements and the lines the modeling results. We modify the caption of the figure 11 as follows: Figure 11: Blind prediction of the long-term pumping results of the mine (point PM), calibrated with the SR4-1 cross-hole test. This pumping lasted 4 months, and its effects reached all observation points. Measurements are represented by circles and model results are represented by a continuous line.

Table 1: The storativity values here are quite different from the ones provided in Figure 5 . The storativity in the fig 5 comes from the hydraulic test interpretation, each interval at a time representing the media as infinite and homogeneous; the extracted water comes from aquifer decompression. These low storativity values are representative of a low-confined aquifer, these parameters have been used as initial estimates during the calibration period of the 3D model. Table 1 shows the final parameters obtained after 3D model calibration, where the aquifer has been represented with its main heterogeneities. The higher values of storativity are related to the shallow aquifer (lehm), where the water is extracted from the rock interconnected porous. Lower values account for the reduction in water pressure due to the medium decompression, since 
water in confined aquifers does not come from porosity.

We thank the reviewer for the detailed and constructive nature of his comments, which we acknowledge in the revised version of the paper.

Interactive comment on Solid Earth Discuss., doi:10.5194/se-2016-27, 2016.

Please also note the supplement to this comment:

http://www.solid-earth-discuss.net/se-2016-27/se-2016-27-AC1-supplement.pdf

Interactive

comment

Interactive comment on Solid Earth Discuss., doi:10.5194/se-2016-27, 2016. 


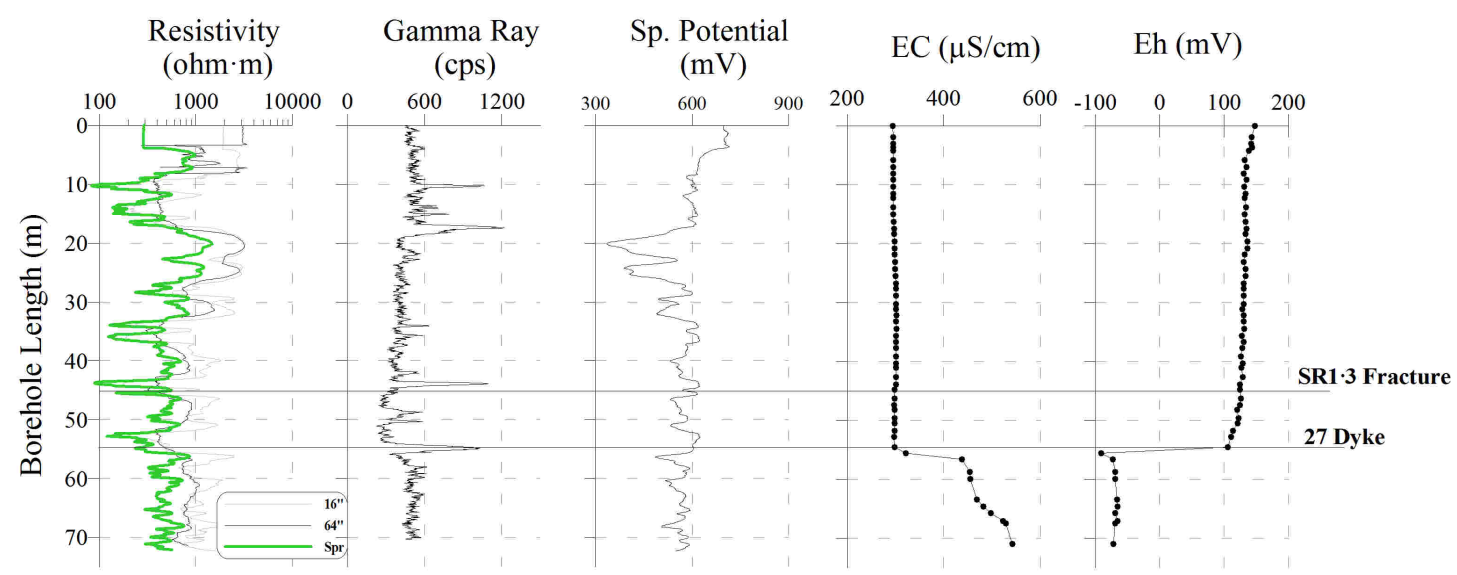

SED

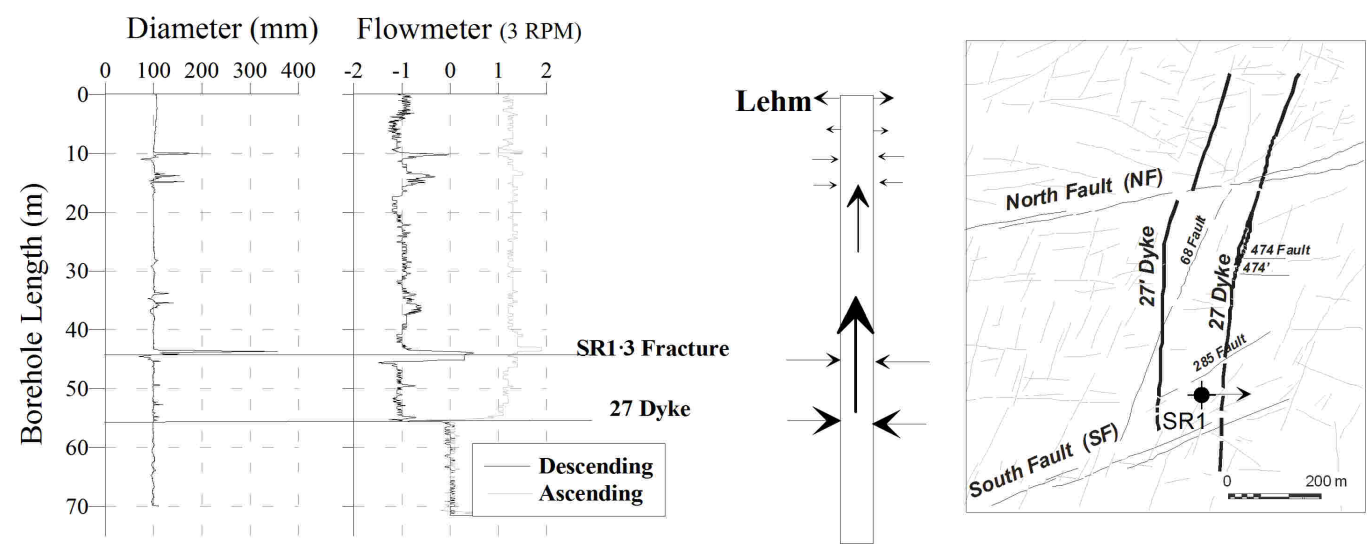

Fig. 1. Figure 4: Some of the chemical and geophysical logs recorded at borehole SR1, which helped to identify dyke 27 and fracture SR1-3. The chemical logs only display the effect of dyke 27 , because all upp 